muscular substance is healthy, and with increased work it hypertrophies, and, acting with great vigour, sends the blood backwards as well as forwards with great force. While a feebly-contracting auricle may produce waves in a thinwalled vein, it requires a greater force to distend the spongelike substance of the liver. In cases of functional dilatation the proximate cause of the dilatation is the weakness of the muscular walls of a heart, so that instead of a hypertrophic muscle producing an abnormally powerful contraction, there is a weakened muscle producing an abnormally feeble contraction. Whether the explanation be sufficient or not, I have sought carefully among a very large number of patients (amounting to many hundreds), with a venous pulse of the auricular type due to functional dilatation, but I have never found a true liver pulse.

The evidence for the statements here made is based on the examination of 7 cases of tricuspid stenosis ; 5 of these cases have had the condition confirmed by post-mortem examination. While these cases are too few for one to be absolutely dogmatic, yet they are more numerous than usually falls to the experience of any single observer. A very large number of cases of liver pulsation of the ventricular type, due to great tricuspid incompetence and other cases of heart disease where there was no stenosis of the tricuspid orifice, have been carefully examined. In no instance, except those mentioned, has there been the slightest evidence of the liver pulse of the auricular type.

\section{A CASE OF ANEURYSM OF THE HEART.}

BX T. SYDNEY SHORT, M.D.,

Physician to the Infirmary and Assistant Physician to the General Hospital, Birmingham.

W. H., aged 33 years, a small and somewhat delicate-looking man, first came under my nqtice in March, 1893. He was suffering from syphilitic enlargement of the testicles; the primary sore having occurred when he was i 7 years of age. I had occasion to examine the heart carefully, and I know that nothing abnormal was then detected from physical examination. Nearly three years elapsed, and in December, 1895, he came to see me, complaining of dyspnca on exertion, dry cough, general weakness, and loss of appetite, all of which had existed for six weeks. His heart was enlarged, the apex was just outside the vertical nipple line, and a loud systolic murmur could be heard almost all over the cardiac area, and was loudest at the apex. The pulse was about roo a minute, of fair quality and regular. The lungs were quite free from adventitious sounds, but it was noted that with inspiration cogwheel interruptions existed all down the front of the right side. These were not heard at all on the left side. He said that soon after I first saw him in 1893 he gave up his work as a stamper, because he felt unable to bear the strain of so arduous an occupation, and took a small beerhouse. $\mathrm{He}$ was, and always had been, an abstemious man himself, a statement his wife corroborated, and as he was now doing no hard work he could not account for his heart trouble in any way. He had never had rheumatism or scarlet fever. For six months he was under my treatment, and improved very much on digitalis, strophanthus, and iron, so that in June of I 896 he was able to get up and downstairs without any dyspncea, and felt well in himself. 1 . The heart's apex was now in the nipple line, the action was regular in rhythm but occasionally varied a little in force; the pulse was 96 ; the loud systolic murmur persisted. Forfourmonths he went on very well without any treatment, and then one day hecarried several buckets of water up and downstairs, and washed out a cellar floor. He felt very fatigued after this; the dyspnœe returned, and some swelling of the feet ensued. This was in October of 1896, and he came once more to see me. He looked very ill. His face was swollen and of a peculiar leaden hue, suggesting argyria, but differing from that condition in that the shadows alone were blue, and the lighter parts of the face, namely, the cheeks and the forehead, were of a waxy and deathly pallor. The heart at this time was much enlarged; the apex beat was in the fifth space, half an inch external to the nipple line, and diffused. There was marked epigastric pulsation. A loud harsh systolic murmur was heard all over the cardiac area and, as before, was most distinct over the apical region. The second sound at the base was reduplicated. The veins of the neck were distended but did not pulsate; the whole of the lower part of the neck looked bloated and swollen. The liver was enlarged and tender; the spleen was not enlarged; the urine contained no albumen. He said he was vomiting all his food, a result, I thought, of congestion of the stomach. He had dyspnœa unless at rest, and complained principally of a distressing bursting feeling over the heart, eased by lying flat on his back.

It was a most unusual sight to see a man livid, and apparently dyspnœic, comfortable in the recumbent posture only, and unable to sit up without distress. From the symptoms and the complete absence of any signs of aortic aneurysm I thought there must be some communication between the right and left sides of the heart : and knowing that he was well until his 33 rd year, and seeing that his nails were only just beginning to club, I thought it unlikely that he suffered from any congenital defect of his heart. It seemed more probable that he suffered from some syphilitic disease of the septum and this was the diagnosis made. He was so much worse altogether, that I advised him to come into the hospital under the care of Dr. Simon, who has most kindly allowed me to make 'use of the hospital notes of the case. Dr. Simon agreed with me in thinking that there was some defect in: the cardiac septum causing admixture of the arterial and venous blood. Careful dieting and half-minim doses of creasote in capsules relieved his sickness, but otherwise he was not improved, and, becoming restless and fidgety, he decided to go home after a fortnight's stay in the wards.

After he left the hospital I saw him several times with Dr. Vincent Jones, who took charge of the case and visited him daily. The cdema increased with alarming rapidity, spreading from the legs to the penis and scrotum, then involving the lumbar region, and finally the skin of the chest and back. His colour varied from day to day in the depth of the cyanosis, but was always of the peculiar livid leaden colour already mentioned. The heart sounds varied also; some days distinct presystolic and systolic murmurs were heard over the apical region with marked triple rhythm of the beat, and within a few hours the rhythm would become double again, with only a loud blowing systolic bruit heard over the precordia and also over the scapular region at the back of the chest It may be especially mentioned, in face of the occe. sional presystolic murmur, that the usual signs of mitral stenosis had been quite absent throughout. More than once a distinct to-and-fro friction was heard, very like a pericardial rub, but there was never any evidence of distension of the pericardial sac with fluid. He insisted upon getting up for some hours every day, and seemed no worse than when he was in bed. His great trouble lay in attacks of intense dyspnœa, which occurred once or twice in the first week, and nearly killed him. He declared that they began with wind in the stomach, and were eased when he could belch it up. Keeping the stomach as empty as possible, and especially forbidding large quantities of fluid food, eased him considerably. With the exception of these attacks he never suffered from shortness of breath, so long as he abstained from moving about, throughout the whole of his illness. No drug seemed now to have any beneficial effect; digitalis, I thought, made him worse. He wandered at night, and latterly in the day time as well. He died quite suddenly and quietly on the night of the fourteenth day after he left the hospital. His wife was with him at the time. He spoke to her and said that.he felt very tired and wanted to go to sleep; then he turned over on his side, and in about ten minutes his jaw dropped and he changed colour. There was no dyspnoic paroxysm at the end. Three days before his death his left axillary vein became plugged, causing œdema $c$. the arm and hand and much pain.

\section{NECRopsy.}

Report by Dr. Stanley. Permission was granted to examine the heart only. The heart weighed I lb. The sac was somewhat distended, and contained semi-opaque fluid. The surface of the epicardium was irregularly granular, and also showed some chronic thickening, as from previous pericarditis, this being most marked over the surface of the right auricle and upper portion of the right ventricle. At one place there was a fibrous adhesion connecting the two pericardial surfaces. On opening the left ventricle an 
aneurysm of the cardiac wall was found at the upper limit of the ventricle, bulging to the right, and forming a projection at the conus immediately under the pulmonary artery, as the latter is directed to the left. The sac was partially filled with laminated clot, and beyond the clot the surrounding tissues appeared fibrous. The coronary artery close by was much thickened. On examination of the myocardium there was found an irregular fibrosis. The valves showed no marked alteration. The lesion appeared to have begun as a syphilitic deposit with subsequent fibroid change allowing of the formation of a cardiac aneurysm.

\section{REMARKs.}

The unusual symptoms in this case seem to have been due to the obstruction to the flow of blood through the pulmonary and coronary arteries. From the position of the sac it is manifest that when full it would form a distinct block by jutting into the cavity of the right ventricle just below the pulmonary orifice. The diminished quantity of blood passing through the pulmonary artery and the resulting deficiency in its aerration account for the extraordinary colour of the patient during life. No communication existed between the sac of the aneurysm and the right ventricle. The cogwheel interruptions during inspiration which were noted when he was under my treatment in 1893 were not subsequently heard.

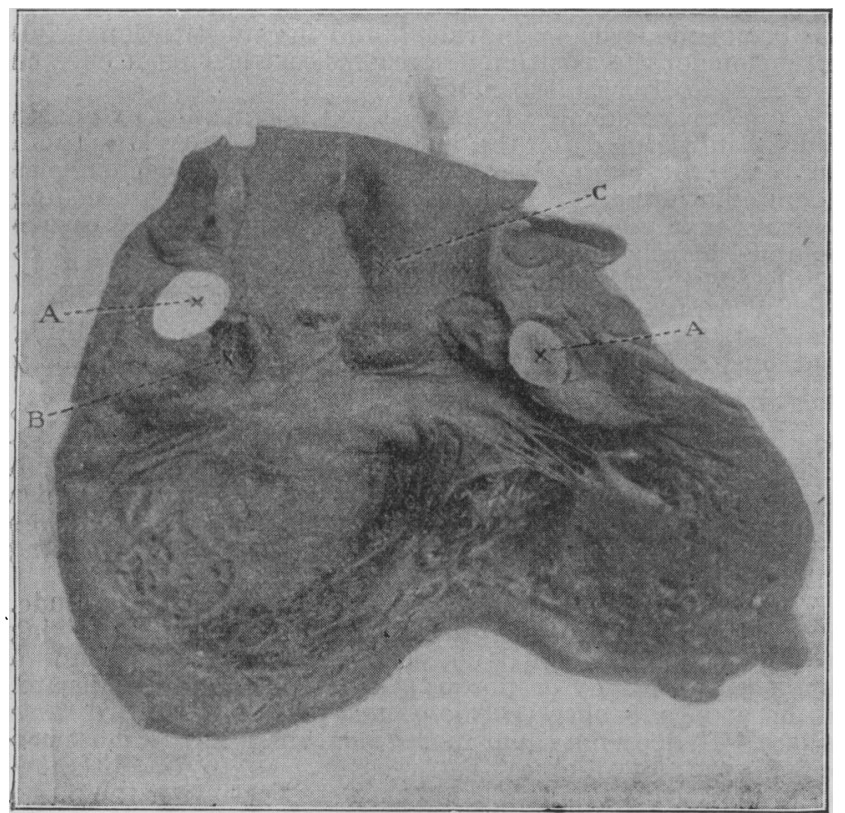

'The photugiaph of the heart, kinaly taken lur me by Mr. Whittles, shows the opening of the aneurysm from the left ventricle.

\section{THE TREATMENT OF TUBERCULOUS DISEASE OF THE HIP IN ITS EARLY STAGES.}

By HOWARD MARSH, F.R.C.S. Surgeon to St. Bartholomew's Hospital.

In the British Medical Journal of April 24th is a paper by Mr. Tobin on Osteotomy of the Femur as a Treatment for Tuberculous Hip Disease in its Early Stages. In the following remarks it will be my endeavour to show that the diffieulties which have presented themselves to Mr. Tobin, and to meet which he has resorted to a proceeding the advisability of which, I believe, many will be inclined to question, have received the attention of surgeons both in England and in America, and have been overcome by methods that can readily be applied. These, it may be added, have been several times described in surgical literature in the course of the last twenty years.
In the first place, Mr. Tobin holds that in early hip disease the limb is flexed, abducted, and everted-the position of greatest ease-because the joint is distended with fluid. But is this the case? Large effusion in early tuberculous disease of those joints which are superficial enough to allow an investigation of this point-the hip, the knee, and the ankle -is seldom present, and I am not aware of any evidence to prove that the hip differs from the other joints in this respect. The probability seems to be that the hip, like the other joints, is placed in the position of greatest ease, not because it is distended with fluid, but in order that the swollen and sensitive soft structures may as far as possible be placed in a state of relaxation-one of the principal elements in physiological rest. The position is easily understood when we remember that it is exactly the same as that which is assumed when we sit down in an easy attitude after exercise, with the thighs flexed, the knees separated, and the feet crossed. In this position all the ligaments as well as the different parts of the capsule of the joint are relaxed. The familiar experiment of Mr. Swann, which Mr. Tobin quotes, no doubt shows that the capsule can accommodate the greatest quantity of fluid when the limb is flexed, abducted, and everted. But that the limb assumes this position in early disease is no evidence that the joint is distended. All joints, including the hip, tend, when they are inflamedwhether they contain fluid or whether they do not-to assume their respective positions of greatest ease.

Speaking of the use of weight extension, Mr. Tobin says that this method "does not act in the way it is represented as doing in the plates in handbooks of surgery. In these" he continues, "you see a patient with a weight attached to the limb lying supine, his back and knee flat and both touching the mattress. What really happens is this; if the weight is heavy enough to keep the leg straight the spine is dragged into a position of lordosis; if it is less heavy there is less straightening of the limb and less lordosis, in which case the lordosis is an indication of force exerted on the joint to its discomfort." I do not know to what plates in any handbooks Mr. Tobin alludes, but the statement seems hardly to convey the whole truth, for certainly many of the best handbooks of the day avoid the error which he mentions, and state correctly how weight extension ought to be used for the hip. This is the case with Erichsen 1 Holmes's System, ${ }^{2}$ Walsham ${ }^{3}$ and D'Arcy Power ${ }^{4}$ while in Treves ${ }^{5}$ the matter, though its importance would have fully justified its introduction, is passed over without notice, so that the mistake which Mr. Tobin has in view is not made. It is twenty-one years ago since in the Hunterian Lectures delivered at the College of Surgeons I pointed out that when weight extension is applied while the limb is in the position which Mr. Tobin so justly criticises the force employed acts, not as extension, but as leverage, for the femur is used as a lever, the weight suspended from the foot acts as the power and the acetabulum as the fulcrum (see Fig. 1) ${ }^{7}$ so that instead of relieving pressure between the head of the femur and the acetabulum it tends directly to increase it.

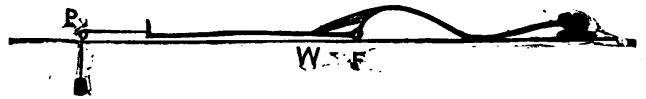

Fig. r.-From Marsh's Diseases of the Joints and Spine, Cassell and Co., r895.

This subject was again discussed in the first and in the second editions of Diseases of the Joints, which appeared in 1886 and 1895 , and in a chapter on interosseous pressure the following appears: "Yet there lies at the bottom of the successful application of weight extension a principle (vide infra) which is frequently overlooked, with the result that instead of acting so as to relieve interosseous pressure by drawing the surfaces out of abnormally close contact, extension has exactly the opposite effect, for it brings the articular ends still more firmly together ;" and "if the parts are examined when the weight has been applied" (in the wrong manner) "it will be found that the limb has come down into the horizontal position, while the pelvis has been rotated so as to produce curvature of the lumbar spine forwards. (Fig. 1.) This change in the position of the limb, however, does not alter the force that is being employed. The force is leverage still, and interosseous pressure is still in action.' 